\title{
Regional disaster impact analysis: comparing input-output and computable general equilibrium models
}

\author{
Elco E. Koks ${ }^{1}$, Lorenzo Carrera ${ }^{2}$, Olaf Jonkeren ${ }^{3}$, Jeroen C. J. H. Aerts ${ }^{1}$, Trond G. Husby ${ }^{3}$, Mark Thissen ${ }^{3}$, \\ Gabriele Standardi ${ }^{2}$, and Jaroslav Mysiak ${ }^{2}$ \\ ${ }^{1}$ Institute for Environmental Studies (IVM), VU University Amsterdam, Amsterdam, the Netherlands \\ ${ }^{2}$ Fondazione Eni Enrico Mattei (FEEM), Venice, Italy \\ ${ }^{3}$ PBL Netherlands Environmental Assessment Agency, The Hague, the Netherlands \\ Correspondence to: Elco E. Koks (elco.koks@vu.nl)
}

Received: 30 September 2015 - Published in Nat. Hazards Earth Syst. Sci. Discuss.: 24 November 2015

Revised: 29 June 2016 - Accepted: 15 July 2016 - Published: 16 August 2016

\begin{abstract}
A variety of models have been applied to assess the economic losses of disasters, of which the most common ones are input-output (IO) and computable general equilibrium (CGE) models. In addition, an increasing number of scholars have developed hybrid approaches: one that combines both or either of them in combination with noneconomic methods. While both IO and CGE models are widely used, they are mainly compared on theoretical grounds. Few studies have compared disaster impacts of different model types in a systematic way and for the same geographical area, using similar input data. Such a comparison is valuable from both a scientific and policy perspective as the magnitude and the spatial distribution of the estimated losses are born likely to vary with the chosen modelling approach (IO, CGE, or hybrid). Hence, regional disaster impact loss estimates resulting from a range of models facilitate better decisions and policy making. Therefore, this study analyses the economic consequences for a specific case study, using three regional disaster impact models: two hybrid IO models and a CGE model. The case study concerns two flood scenarios in the Po River basin in Italy. Modelling results indicate that the difference in estimated total (national) economic losses and the regional distribution of those losses may vary by up to a factor of 7 between the three models, depending on the type of recovery path. Total economic impact, comprising all Italian regions, is negative in all models though.
\end{abstract}

\section{Introduction}

In the last few decades we observe an increasing amount of economic activity in areas prone to natural disasters in the world, in combination with a rising frequency of extreme weather and climate events (IPCC, 2012). As a result, the need for high-quality disaster impact models is becoming more urgent. In response, a large number as well as a variety of models have been applied to study the economic impacts of disasters. While the most common economic models for disaster impact analysis are input-output (IO) and computable general equilibrium (CGE) models, an increasing number of scholars employ hybrid models, combining the two or either of them with different (partly noneconomic) models (Baghersad and Zobel, 2015; Carrera et al., 2015; Koks et al., 2015). This wide variety of models, however, leads to an important question: how should (differences in) the outcomes of the models be interpreted?

While both IO and CGE models are widely used, a comparison between their results has only been done on a theoretical level (e.g. Rose, 1995, 2004; Okuyama and Santos, 2014) or on the basis of different case studies (e.g. Okuyama, 2010). Few studies exist in which both model types are empirically compared in a systematic way for the same case study and geographical area using identical input data $(\mathrm{Hu}$ et al., 2014; West, 1995). Such a comparison is highly valuable from both a scientific and policy perspective as the magnitude and spatial distribution of losses may vary. It is possible that investments in risk reduction appear justified on account of a certain model while disproportionally high ac- 
cording to another model. Alternatively, regions not directly affected but with trade relations with a region hit by a natural disaster may display either gains or losses depending on the choice of the model. Regional disaster impact loss estimates resulting from a range of model outcomes facilitate better decisions and policy making.

In this study we analyse the disaster impact for two flood scenarios in the Northern Italy (Po River basin district) area using three models: two hybrid IO models and a regional CGE model for Italy. We first discuss the main model characteristics. After that, we apply the models and compare their results. The two hybrid input-output models used in this study are the commonly used the Adaptive Regional InputOutput (ARIO) model developed by Hallegatte (2008) and the MultiRegional Impact Assessment (MRIA) model, developed by Koks and Thissen (2014). The CGE model used in this study is a regionalized version of the CGE model developed by Standardi et al. (2014), which has been applied already in Carrera et al. (2015) for a disaster impact analysis. In the remainder of the paper the CGE model will be indicated as IEES (Italian Economic Equilibrium System).

The paper proceeds as follows. In Sect. 2, we discuss the valuation of economic losses and provide an overview on important modelling aspects involved in disaster impact analysis. This section includes both a theoretical comparison between IO and CGE models and a brief overview of the proven model extensions from the literature. This is followed by an explanation of the used models in this comparison exercise and the used data in Sect. 3. In Sect. 4, we present the study area, in Sect. 5 the results of the comparison are presented, and in Sect. 6 they are discussed. Finally, Sect. 7 concludes with providing some lessons learned and recommendations for practitioners and policy makers in the field of disaster risk modelling.

\section{Current practices in disaster impact analysis}

Before turning to the methodological aspects, it is essential to understand what is conceived as a disaster and what types of economic losses are referred to in this paper. A disaster is not equivalent to a natural hazard. According to the revised UNISDR terminology (UNISDR, 2015), hazards are "potentially damaging physical events, phenomena, or human activities" that may cause harm, while disasters are serious disruptions beyond the capacity to coping with the suffered harm. More generally, hazard strikes turn into a disaster when communities or societies at large are unable to cope, with own resources, with the manifold economic, physical, social, cultural, and environmental impacts of hazard strikes. Consequently, hazard research focuses often on modelling physical disrupting events only, while disaster research should always comprise societal impacts (often in economic terms) as well as the post-disaster reconstruction and recovery (Okuyama and Chang, 2004).

\subsection{Economic loss valuation}

In the recent scientific literature on the economic impacts of disasters, there is often a differentiation between two types of losses: stock and flow losses (Bockarjova, 2007; Okuyama and Santos, 2014; Okuyama, 2003; Rose, 2004). Stock losses can be defined as damage that arises from destruction of physical and human capital. Tangible stock losses result from asset damage. Flow or production losses can also be used to address damage on productive capital but more frequently flow losses refer to business interruption and interference in up- and downstream supply chains (Okuyama and Santos, 2014). In contrast to asset losses, flow losses are often the main focus in the economic literature; see e.g. Hallegatte 2008; Rose and Wei, 2013; Okuyama, 2014). In the rest of the paper, we will refer to flow losses as output losses. These flow losses are commonly subdivided into short-term (up to 5 years) and long-term (more than 5 years) effects (Cavallo and Noy, 2009).

\subsection{IO models vs. CGE models: a theoretical comparison}

The most frequently used models in the current disaster impact modelling literature are econometric models, social accounting matrix (SAM) models, IO models, and CGE models. Econometric models, based on time-series data, have the advantage of being statistically rigorous and have predictive skills, but they can only provide estimates of the total (aggregated) impacts (Rose, 2004). Reduced-form estimates of disaster losses from econometric models reveal little about the potentially substantial ripple effects of a disaster. SAM models, in contrast, which are very similar to IO models, are capable of measuring the different orders of indirect effects throughout the system of different economic agents Okuyama and Sahin, 2009; Seung, 2014). SAM models are, however, rarely applied. One of the main reasons might be that SAMs are not often constructed by national bureaus of statistics, and if they are constructed they are specifically built for CGE models since they are a prerequisite of CGE models.

IO and CGE are the most commonly applied models to assess the economic impacts of disasters. In general, a standard IO model can be described as a static linear model which presents the economy through sets of interrelationships between sectors themselves (the producers) and others (the consumers). A neoclassical CGE model, however, is a system of equations in which perfect competition is assumed in products where market and factor endowments are fully employed. In each region a representative firm maximizes profits under a technological constraint and a representative household maximizes consumption utility under a budget constraint. The macroeconomic closure is neoclassical, meaning that investments are determined by savings and demand for factors of production equals their (fixed) supply. A 
fixed proportion of the household income is allocated to savings; the global bank collects all the world savings and uses them for investments which are perfectly mobile at the global level. The trade balance is endogenously determined. The IO and CGE models are characterized by a number of differences. The most important difference between IO models and CGE model is the partial economic analysis in IO modelling vs. the general equilibrium analysis in CGE modelling. The general equilibrium approach stands for a closed economic system where not only all products that are produced are used elsewhere but also all income earned is spent on different products (possibly via savings on investments). The general equilibrium approach describes the complete economy, accounting for all monetary and nonmonetary flows. They are demand-driven models where higher/lower income earned in a region does not lead to more/less products demanded. Moreover, how the system is closed with respect to the financial markets, will to a large extent, affect the type and the distribution of the effects (Taylor and Lysy, 1979; Thissen and Lensink, 2001). In this paper we use a CGE model with a neoclassical savings-driven closure, which is the most commonly applied in the literature.

As shown in Table 1, we can define a number of other differences. First, in an IO model the costs of substitutions of commodities (which would change the technical coefficients) are costly and unlikely to be made in the short run (Crowther and Haimes, 2005). For an IO model to be suitable, a disturbance must be long enough to take effect but also short enough to avoid excessive substitutions. Shortterm effects are therefore often analysed with input-outputbased approaches, while an analysis of long-term effects require a (price) flexible approach, which is possible with CGE models (Thissen, 2004). Second, IO models are often praised for their simplicity and ability to explicitly reflect the economic interdependencies between sectors and regions for deriving higher-order effects. CGE models, however, are more complicated because they include supply side effects and allow for more flexibility due to their nonlinearity regarding inter-sectorial deliveries, substitution effects and relative price changes. Third, as a result of the different economic mechanisms, the outcomes often differ as well. Due to their linearity and incapability to include effects of resilience measures (the price mechanism being an important one), IO models are often considered to overestimate the impacts of a disaster. CGE models, in contrast, are said to underestimate the impacts because of possible extreme price and quantity changes which result from the included elasticities (Rose, 2004). Fourth, substitution of products and production factors between regions and producers are not possible in the standard Leontief-based IO model, while they are likely to occur in a post-disaster situation. Substitution effects are taken into account in CGE models in that more flexible functional forms are applied, such as functions based on Cobb-Douglas (CD) and constant elasticity of substitution (CES). Last, IO models generally do not handle supply con- straints but model a supply perturbation by means of an artificial demand reduction. CGE models include reduced supply capacities.

To overcome some of the shortcomings of traditional IO models for disaster risk modelling, several extensions ${ }^{1}$ have been developed. For instance, Okuyama et al. (2004) have explicitly included a time horizon by applying a sequential industry model, which allows for an assessment of the effect of a disaster dynamically over time. Another model which has been widely used and applied is the Inoperability InputOutput Model, developed by Santos and Haimes (2004). This model has also been dynamically extended (the DIIM) to include the time aspect. Besides adding a time and resilience dimension, IO models have also been extended spatially by applying an interregional model instead of the traditional single-region model (see e.g. Cho et al., 2001; Kim et al., 2002; Okuyama et al. 2004; Crowther and Haimes, 2005; MacKenzie et al., 2012). CGE models have been extended and further developed as well, to make them more suitable for the modelling of disasters. For instance, Rose and Liao (2005) have developed a CGE model, where they recalibrated the production function to account for resilience. In spatial CGE models (e.g. Tsuchiya et al., 2007; Shibusawa et al., 2009) the distance between agents in the economy is explicitly incorporated as a dimension (i.e. interregional modelling).

\subsection{Hybrid models}

Hybrid models are either a combination of IO and CGE models (i.e. CGE modelling characteristics) or a combination of either of them with another type of model. Koks et al. (2015) have coupled an IO model with a biophysical model to improve the accuracy of modelled economic disruption. Carrera et al. (2015) and Ciscar et al. (2014) have coupled a CGE model with a biophysical model. Husby (chapter 7, 2016) combines a Spatial CGE model with an agent-based model of opinion dynamics to analyse macroeconomic effects from an increase in public concern. As can be interpreted from in den Bäumen et al. (2015), for instance, traditional multiregional input-output modelling may result in overestimation of the effects in the non-affected regions when not considering the substitution possibilities between the imports from different

\footnotetext{
${ }^{1}$ In this paper we differentiate between extended models and hybrid models. An extended model is defined as either a traditional IO or CGE model which is extended by a specific module to make it more compatible for the proposed research question. Examples are Santos and Haimes (2004) and Rose and Liao (2005). A hybrid model, however, is defined as an IO or CGE model which is combined with a different (non-)economic model. More specifically, the IO or CGE model is altered in such a way that only the most important theoretical rules are kept. The model is adjusted in such a way that it cannot be directly described anymore as an IO or a CGE model as such. Examples are Hallegatte (2008), Carrera et al. (2015), and Koks et al. (2015).
} 
Table 1. Comparison of IO and CGE approach on important modelling characteristics.

\begin{tabular}{lll}
\hline Characteristic & IO & CGE \\
\hline Time horizon & Short-run & Short-, medium-, and long-run \\
Substitution & Not possible in traditional model & Possible \\
Mathematical complexity & Linear/simple & Nonlinear/advanced \\
Model type & Partial economic analysis & General equilibrium (system) effects \\
Supply side & Lack of resource constraints & Handles supply constraints \\
Sector interdependencies & Accounted for via technical coefficients & Accounted for via (cross-)elasticities \\
Resilience & Generally under recognized & Primarily price mechanism \\
Estimation accuracy & Overestimation of disaster impact & Underestimation of disaster impact \\
\hline
\end{tabular}

regions. CGE models, in contrast, have the potential to underestimate the impacts because of possible extreme substitution effects and price changes (Rose, 2004) especially in the short run. One of the most well-known hybrid IO model with CGE characteristics is the ARIO model, developed by Hallegatte $(2008,2014)$. ARIO allows for production bottlenecks and rationing (see also Sect. 3.1). Another example is the TransNIEMO model, which is a coupling between a multiregional IO model and a transportation network model, which assesses economic consequences arising from disruption of highway network (Park et al., 2011). Finally, more research is being done recently in combining IO modelling with linear programming (see e.g. Rose et al., 1997; Baghersad and Zobel, 2015; Koks and Thissen, 2014).

\section{Models and data}

Figure 1 shows the methodological approach undertaken in this study. A flood damage assessment is performed on two flood scenarios along the Po River in Northern Italy. The economic disruption, as a result of each of the floods, will be prepared for each model. Stock losses are then translated into flow losses by means of the three economic models. Outputs are systematically compared to investigate the key characteristics of the models and their significance. Table 2 provides a preliminary analysis of the key characteristics of models, based on the descriptions as provided in the following sections.

\subsection{From stock losses to flow losses}

We assess production losses by converting the asset losses (stock) to a reduction in value added (flow). This conversion is done using a CD production function, while assuming constant returns to scale. A standard CD production function, as shown in Eq. (1), translates the production inputs, capital $(\boldsymbol{k})$, and labour $(\boldsymbol{l})$ into the amount of output $(\boldsymbol{y})$ per sector, where $\boldsymbol{b}$ is the total factor productivity per sector and $\alpha$ and $\beta$ are output elasticities (Cobb and Douglas, 1928).

$\boldsymbol{y}=\boldsymbol{b}^{\alpha} \boldsymbol{l}^{\beta}$

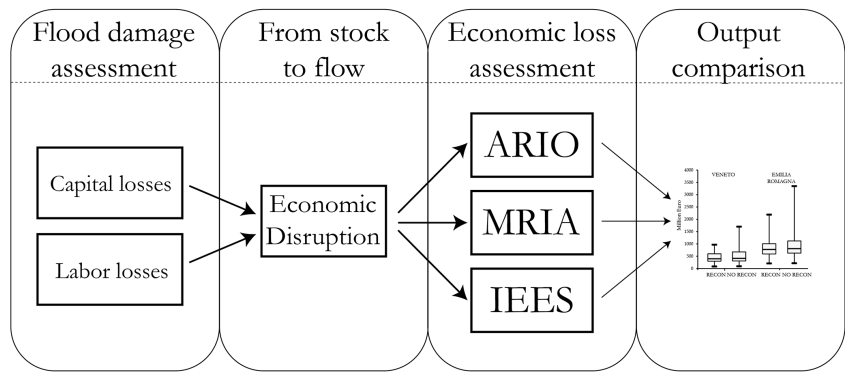

Figure 1. Overview of the different components of the comparison study.

To avoid a possible underestimation of the production losses, the assumption of constant returns to scale is essential (see Koks et al., 2015, for an extensive explanation). In standard input-output modelling, capital and labour belong to the value-added part of the model. As such, the CD function translates the direct damages into a reduction in value added ( $\boldsymbol{y}$ in Eq. 1). Consequently, the change in value added $(\Delta \boldsymbol{y})$ can be translated into losses in total production $(\boldsymbol{x})$. The economic disruption per sector $\left(\boldsymbol{\sigma}_{t}\right)$ is defined as

$\sigma_{t}=\frac{y_{t}}{x_{t}} \frac{\Delta y_{t}}{y}$.

The economic disruption per sector (the right side of Eq. 2) can be seen as the part of the sector in the affected region that is not possible to "operate" (Santos and Haimes, 2004). This disruption, or shock, will be referred to as the sector inoperability vector. The following step is to assess by how much the natural disaster affects the total production. This can be done by multiplying the total production with the sector inoperability vector, as shown by Eq. (3), with $x^{0}$ being the vector of the total production and $\sigma$ as the sector inoperability vector. In Eq. (3), $\boldsymbol{x}_{t}$ is defined as the new production level in time period $t$. In the first run, the new time period is considered to be the new post-disaster economic situation. From the post-disaster situation, we can continue to simulate the short-run recovery period (Koks and Thissen, 2014).

$x^{0}\left(1-\sigma_{t}\right)=x_{t}$ 
Table 2. Key characteristics of the used models.

\begin{tabular}{|c|c|c|c|}
\hline Characteristic & ARIO & MRIA & IEES \\
\hline Production function & Leontief production function & Leontief production function & $\begin{array}{l}\text { Constant elasticity of substitu- } \\
\text { tion production function }\end{array}$ \\
\hline Substitution effects & $\begin{array}{l}\text { Rationing and prioritization } \\
\text { between outputs }\end{array}$ & $\begin{array}{l}\text { Products and production (in- } \\
\text { puts) between regions and pro- } \\
\text { ducers. }\end{array}$ & $\begin{array}{l}\text { Products and production factors } \\
\text { between regions, producers and } \\
\text { inputs. }\end{array}$ \\
\hline Possibility for overproduction & Yes $(25 \%)$ & Yes $(5 \%)$ & Yes (the total VA of Italy) \\
\hline Composition of losses & Value added loss & $\begin{array}{l}\text { Value added loss }+ \text { production } \\
\text { efficiency loss. }\end{array}$ & Value added loss \\
\hline Input data and assumptions & $\begin{array}{l}\text { IO tables/model, production } \\
\text { capacity limitations }\end{array}$ & $\begin{array}{l}\text { Supply and use tables, linear } \\
\text { programming. Use of ineffi- } \\
\text { cient technologies } \\
\text { possible, capacity limitations }\end{array}$ & $\begin{array}{l}\text { Social accounting matrix, } \\
\text { (cross-)elasticities, capacity } \\
\text { limitations }\end{array}$ \\
\hline Regional aspect & $\begin{array}{l}\text { Demand = supply (no specific } \\
\text { difference between regions) }\end{array}$ & $\begin{array}{l}\text { Maximum regional production } \\
\text { capacity }\end{array}$ & $\begin{array}{l}\text { Rigid and flexible re-allocation } \\
\text { of production factors and trade }\end{array}$ \\
\hline
\end{tabular}

\subsection{The ARIO model}

For the purpose of this paper the ARIO model is made multiregional. The model considers the (multi)regional economy consisting of households and various industries which produce, import, and export goods and services. The model accounts for interactions between sectors through demand and supply of consumption goods. Besides, the model specifically incorporates heterogeneity in goods and services within sectors and the consequences of production bottlenecks and flexibility in recovery of total output (Hallegatte, 2014).

Let us briefly explain the main modelling steps in the ARIO model. First, the model starts by calculating the maximum possible production capacity. Following this, the reconstruction demand is determined from the direct economic damage (and considered as additional final demand). This enables an assessment of the required production available to satisfy the final and reconstruction demand (Koks et al., 2015). Subsequently, the maximum possible production capacity and the required total production are compared to identify the production available for reconstruction, final demand, and export. If less production is available than required to satisfy all demand, the model will ration the demand. This process of prioritization and rationing can be interpreted as a form of substitution, as stated in Hallegatte (2008). It should be noted, however, that this type of substitution is different than the substitution considered in the other two models. In this process, the ARIO model only substitutes between outputs, whereas the other models specifically substitute between inputs.

As a result, the remaining reconstruction demand and the remaining damage in capital and labour can be identified (Hallegatte, 2014; Koks et al., 2015). The output of the model, remaining reconstruction demand, and remaining damage in capital and labour can be used as inputs to cre- ate an iterative process that simulate time steps until the predisaster final demand is met and reconstruction is completed.

The last step of the model is to calculate the loss in value added for each time step, based on the reduction of the maximum production capacity. Consequently, the output losses are calculated as the difference between the total value added without flooding and the total value added with flooding for each time step (Koks et al., 2015). For a more extensive description of the model, see Hallegatte $(2008,2014)$.

\subsection{The MRIA model}

The MRIA model is a tool to assess the short-run economic effects of a natural disaster using a recursive dynamic multiregional supply and use modelling framework, which combines nonlinear programming and input-output modelling techniques. The MRIA model takes available production technologies into account, includes both demand and supply side effects, and includes interregional tradeoffs via trade links between the regions (Koks and Thissen, 2014).

The MRIA model is able to (i) reproduce the baseline (pre-disaster) situation and (ii) assess the impact of an economic shock due to a disaster. In line with standard IO modelling, the model is based on the assumption of a demanddetermined economy. In other words, demand from all Italian regions and the rest of the world has to be satisfied by total supply in all separate regions and the rest of the world. Although this will hold for the total Italian economy, we introduce a supply restriction at the regional level. Industries in the different regions face a short-run maximum capacity. If the demand exceeds this maximum capacity, imports to this region increase in order to satisfy demand. This will cause interregional spillovers because other firms from other regions takeover from firms that are damaged or at their maximum capacity 

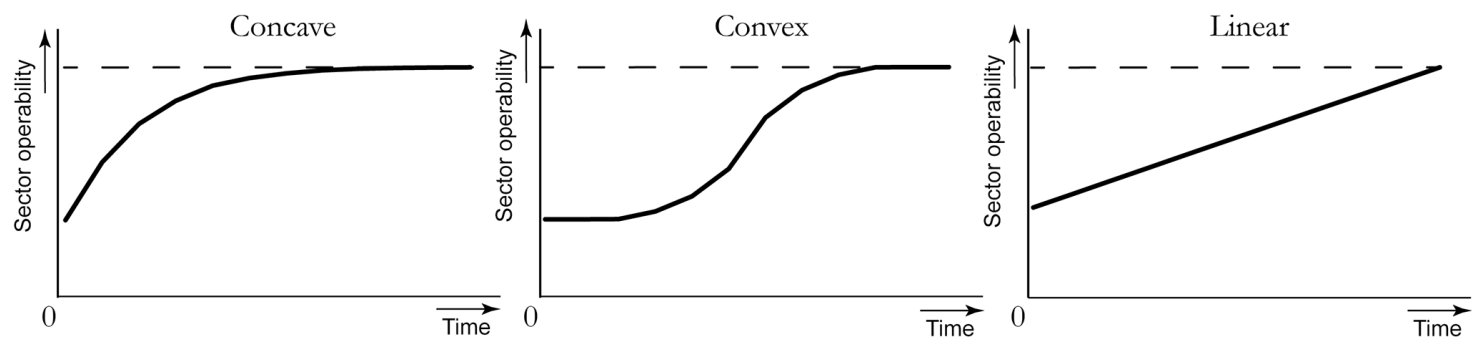

Figure 2. Three recovery curves used in this study.

However, before imports from other regions increase, first other firms that can produce comparable products (although less efficiently) and have slack capacity will take over until they reach their maximum capacity. The MRIA model is based on technologies that are owned by industries and used to make products. In the model, we assume that the technical coefficients matrix describe the technologies used by an industry. Hence, the technologies can be interpreted as the inputs that are required to produce a certain output. Products are produced at the lowest costs, and together with the demand for products in every region this determines which technologies are being used and to what extent. It implies that inefficient technologies are being used to produce products when production with the "optimal" technology is limited due to supply constraints. To avoid very inefficient overproduction of secondary products in the affected region by other industries, it assumed that before a region reaches its maximum regional capacity it will already start importing goods from other regions instead of trying to produce these goods themselves.

Next to the commonly assessed output losses of a natural disaster, the MRIA model also allows us to determine the losses due to the use of inefficient production technologies. These second type of losses, due to the increased inefficiencies in the production process, results in the rise of production costs. The supply and use framework allows for a detailed approach to estimate this effect. In this framework, it is known where the products in final use are produced and which industries use products that were inefficiently produced, thereby increasing their costs. This allows for an allocation of the inefficiency losses to the region of production. For a more extensive description of the model see Koks and Thissen (2014).

\subsection{The IEES model}

The IEES model is a sub-national CGE model based on the Global Trade Analysis Project (GTAP) model and database (Hertel, 1997; Narayanan and Walmsley, 2008) downscaled to the 20 Italian NUTS2 regions. Following standard CGE modelling, the IEES model is a system of equations describing the behaviour of the economic agents (representative households and firms), the structure of the markets, and the institutions, as well as the links between them. The representative household in each region maximizes consumption utility flow subject to the budget constraint. The representative firm maximizes profit, choosing the amount of inputs for their production. Primary factors of production, such as land, capital, labour, and natural resources, are owned by households and fixed in supply. The IEES model has a neoclassical structure where factors are fully employed, and the markets are perfectly competitive. All prices of goods and primary factors in the economy adjust such that demand equals supply in all markets. Bilateral trade flowing across the 20 Italian regions is modelled together with trade between regions, the rest of Europe, and rest of the world. The neoclassical macroeconomic closure implies that the difference between regional saving and regional investment is equal to the trade balance of the region. However, the representative household pays taxes that accrue to the regional household. The regional household includes private expenditure, government expenditure, and regional saving in fixed proportions; therefore the regional household collects and pays taxes at the same time. No public budget constraint is considered in the model.

To assess the impacts of a natural disaster, the model relies on the following assumptions: (a) the shock (i.e. the flood) leads to a reduction in the capital stock in the year of the impact; (b) output losses are generated by the disruption of the production, which is related to the loss of assets; and (c) inventories are not considered. Important to note is that IEES model is static; each single "shock" to the economic system translates into a yearly loss of output. For the IEES model, we apply a rigid and a flexible version. The rigid version considers labour and physical capital as immobile at the subnational level. In addition, the intra-national trade is assumed to be as fluid as the international trade and has therefore the same substitution elasticity. In contrast, in flexible specification labour and capital can move in other sub-national regions according to a constant elasticity of transformation function which determines the sub-country labour and capital supply. Intra-national trade is more fluid, which means that substitution between sub-national products coming from two different Italian regions is bigger than substitution between Italian and foreign products. 


\subsection{Recovery path and duration}

As identified in Sect. 2, an important characteristic which significantly influences the potential total losses is the duration of the recovery period and the type of recovery path. Figure 2 shows three possible paths: concave, convex, and linear (similar paths have been used in Baghersad and Zobel, 2015). The concave recovery path can be interpreted as being quick and smooth from the beginning, as a result of which most of the area is recovered within a couple of time steps. The convex path can be interpreted as delayed recovery. This may occur because emergency and repair activities are hampered. The convex path implies slow recovery in the immediate post-disaster time periods and quicker recovery later. Finally, the linear recovery path is assumed to be a "way through the middle" and based on the assumption that capital available for reconstruction is evenly distributed over the recovery period. Due to the large uncertainty in the potential recovery path and duration, it is worthwhile to test the results between these three recovery paths. As such, the three recovery paths can be interpreted as a "sensitivity analysis" of the results. In this exercise, the recovery paths are exogenously coupled to the three models. More specifically, for each individual model iteration we exogenously determine how the economy has recovered, based on one of the three recovery curves. This allows for a consistent comparison between the three modelling frameworks. Furthermore, we assume a full recovery in 1 year in all the models.

\subsection{Data}

For the ARIO and IEES model, the data are based on GTAP 8 database (Narayanan et al., 2012) and ISTAT (Italian National Statistical Institute) data. In order to get a sub-national database for each of the 20 Italian regions and derive the bilateral trade flows between them, we integrate GTAP with information stemming from ISTAT. We split the GTAP data for Italy by using the ISTAT shares on valued added, labour, and land for each sector and Italian region. To reconstruct the regional domestic demand and bilateral intra-national trade flows we make use of ISTAT transport data. An extensive description of the methodology can be found in Standardi et al. (2014) and Carrera et al. (2015).

For the MRIA model, a regionalized version for Italy of the European multiregional supply and use table is used, developed by PBL Netherlands Environmental Assessment Agency (Thissen et al., 2013). The table distinguishes 20 different Italian regions (NUTS2 level), 15 sectors, and 59 products, allowing for a detailed disaster impact analysis. Supply and use tables contain more information compared to IO tables since the separate industries and commodities of the supply and use tables are combined in the IO tables using one out of several standard assumptions about technologies.

Because the MRIA model is based on supply-use tables, whereas the IEES and ARIO models are (initially) based on a social accounting matrix, a few steps are required to make sure the model outputs can be compared consistently. First, it should be noted that there is a slight discrepancy in the specific sectors between the two datasets. Appendix Table A1 shows the list of sectors, aggregated to an overlapping form. The table in Table A1 shows a total of eight aggregated sectors, varying from agriculture to industry to services. Second, both datasets are translated to 2004 Euro values. Third, after the translation to 2004 values, the datasets are made consistent in terms of gross regional product (GRP) and industrial gross value added (GVA). Important to note is that we interpret the results on a regional scale (total economy) and do not compare the model outputs on a sectoral level.

\section{Study area and asset losses}

For the comparison, we consider two simulated floods in the Po River basin in Northern Italy. As shown in Fig. 3, the two floods affect the administrative regions of Veneto and Emilia-Romagna in the downstream part of the basin. The two flood events considered in this study represent the result of a simulation produced by ARPA Emilia-Romagna (Regional Agency for Environmental Protection). The exercise simulates two levee breach scenarios around the municipality of Occhiobello: one on the southern and one on the northern levee. The southern breach inundates the Emilia-Romagna region, while the northern breach the Veneto region. The case study in Veneto and Emilia-Romagna is selected for their relevance in the Northern Italy economy. Although being simulated, the scenarios are not totally unrealistic. Occhiobello is famous for being the location where in 1951 Italy experienced one of the largest inundations on record. The location is also reported to be one of the most vulnerable sections along the Po River levee system. In 1951 the levee breach (northern) inundated more than 100000 ha of urban and agriculture land in Veneto, causing large economic losses and more than 100 causalities. The river discharge associated with the levee breach considered in this study corresponds to the discharge recorded during the 2000 Po River flood, which was approximately the discharge recorded in 1951 (10300 vs. $9750 \mathrm{~m}^{3} \mathrm{~s}^{-1}$ ). The flood caused by a left-bank breach on the Po River levee affected the Veneto region. It resulted in inundation of mainly agricultural land and dispersed small settlements. The flood case on the right-bank breach of the Po River levee affected Emilia-Romagna. It resulted in substantial flooding of industrial areas, in addition to agricultural and residential areas. Table 3 shows the result of the asset loss assessment, performed with the use of depth-damage curves $^{2}$.

\footnotetext{
${ }^{2}$ Please consult Merz et al. (2010) and Jongman et al. (2012) for a complete explanation of the use of depth-damage curves for disaster risk assessments. A complete explanation of this method is out of the scope of this paper.
} 
Table 3. Asset losses of the affected regions

\begin{tabular}{lc}
\hline $\begin{array}{l}\text { Region name } \\
\text { (NUTS2) }\end{array}$ & $\begin{array}{c}\text { Asset losses } \\
\text { (in million Euro) }\end{array}$ \\
\hline Veneto & 1873.6 \\
Emilia-Romagna & 1890.2 \\
\hline
\end{tabular}

Table 4. Total economic losses in Italy (in million Euro).

\begin{tabular}{lrrcc}
\hline \multicolumn{5}{c}{ Concave recovery path } \\
\hline Flooded region & ARIO & MRIA & IEES - Rigid & IEES - Flex \\
Veneto & 597.9 & 84.9 & 106.7 & 106.9 \\
Emilia-Romagna & 1178.3 & 264.3 & 207.4 & 207.9 \\
\hline \multicolumn{5}{c}{ Convex recovery path } \\
\hline Flooded region & ARIO & MRIA & IEES - Rigid & IEES - Flex \\
Veneto & 969.5 & 597.3 & 361.1 & 361.9 \\
Emilia-Romagna & 2175.0 & 950.4 & 701.8 & 703.8 \\
\hline \multicolumn{5}{c}{ Linear recovery path } \\
\hline Flooded region & ARIO & MRIA & IEES - Rigid & IEES - Flex \\
Veneto & 967.1 & 573.9 & 397.3 & 398.2 \\
Emilia-Romagna & 2191.5 & 923.9 & 772.2 & 774.4 \\
\hline
\end{tabular}

As can be seen from Table 3, asset losses are very similar for both flood scenarios. There are, however, important differences in the composition of the losses. First, asset losses within industrial areas are more than twice as large in EmiliaRomagna compared to Veneto. They account for amounts to $15 \%$ of the total losses in Veneto and $35 \%$ of the losses in Emilia-Romagna. Second, asset losses in urban areas are $76 \%$ of the total asset losses for the flood in Veneto, whereas only $52 \%$ for the flood in Emilia-Romagna. Finally, the asset losses in agricultural areas are 9 and $10 \%$ of the total asset losses for, respectively, Veneto and Emilia-Romagna.

\section{Results}

Table 4 shows the total output losses in Italy for the two floods, the three models, and the three recovery paths. The calculations with the ARIO model result in the highest losses for the whole of Italy, for both floods, and for each recovery path. This is in line with expectations from previous literature that IO models may result in higher estimates of losses (e.g. West, 1995; Rose, 2005). The IEES model has, as expected, the lowest output losses in almost every model set-up. The lowest losses for the IEES model can be explained mostly by the perfect substitution across sectors of labour and capital. This means that labour and capital can move from one sector to another without transition cost and may influence the reduction of losses even more than the potential increase in trade.

Only for the concave recover path for the flood in the Veneto region are the losses in the MRIA model slightly

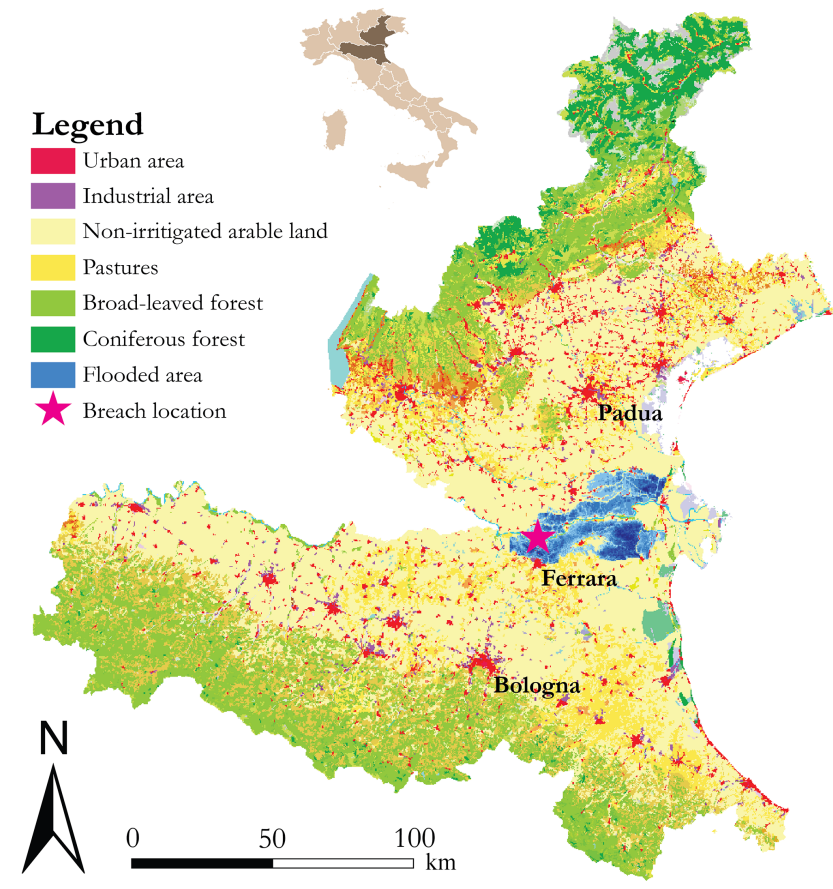

Figure 3. Overview of the study area.

lower. This can be explained on a sectoral level: in the MRIA model, the extra reconstruction demand, which goes directly towards the construction sector, has a clear positive effect on this sector. In the IEES model, this positive effect is marginal. For the convex and linear recovery paths, the higher sectoral losses due to slower recovery largely outweigh this positive effect in the MRIA model. The rigid and flexible versions of the IEES model show comparable results for Italy as a whole. Important to note here is that the difference between the two models only has an effect on the spatial differentiation of the losses (see Fig. 4).

Table 5 shows the losses for the flooded regions region only. It is worth noting that in the affected region the crossmodel differences are much smaller and strongly depend on the recovery path. From Table 4 it becomes apparent that the ARIO-estimated losses for Italy as a whole are almost 6 times larger than the IEES - Flex model for the concave recovery path and the Veneto flood scenario (first row). When considering only the losses of the affected region, this difference is a only factor 0.2 (first row in Table 5). This implies that the largest differences in outcome between the models are occurring in the multiregional effects of the disaster. More specifically, this means that the assumptions regarding multiregional spillover effects (with or without substitution, additional imports, or factor mobility) are important determinants of the final outcomes.

A closer look at the differences for the affected region in Table 5 shows additional divergences between the models compared to Table 4. First, in Table 4 the ARIO model 
Table 5. Economic losses for the affected regions under all model set-ups (in million Euro).

\begin{tabular}{llrrcc}
\hline & & ARIO & MRIA & IEES - Rigid & IEES - Flex \\
\hline Veneto & Concave & 156.4 & 93.9 & 101.8 & 129.6 \\
& Convex & 430.7 & 634.0 & 344.7 & 438.6 \\
& Linear & 434.0 & 605.2 & 379.3 & 482.6 \\
\hline \multirow{2}{*}{ Emilia-Romagna } & Concave & 306.3 & 334.3 & 203.6 & 261.1 \\
& Convex & 863.7 & 1108.6 & 688.9 & 883.7 \\
& Linear & $870.7^{2}$ & $1053.2^{4}$ & $758.1^{1}$ & $972.4^{3}$ \\
\hline
\end{tabular}

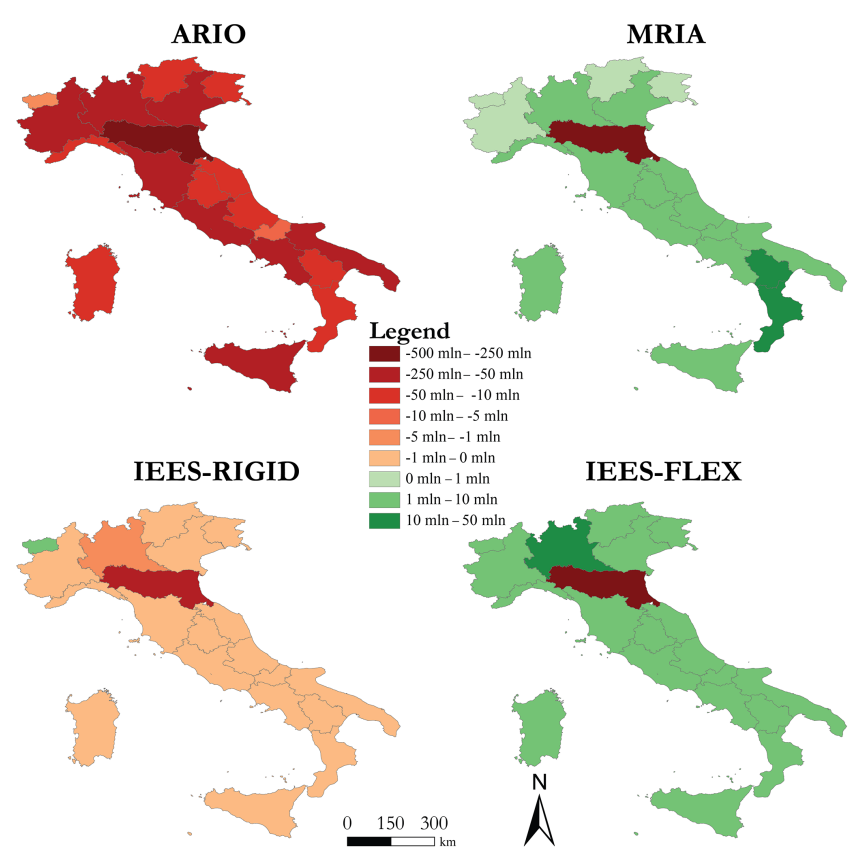

Figure 4. Spatial distribution of losses across Italy for the flood in Emilia-Romagna with the concave reconstruction curve for the four model set-ups.

always predicts the highest losses for Italy as a whole. In Table 5, where only the losses are shown for the affected region, this is only the case for the concave recover path for the Veneto flood event. In all other scenarios, the induced losses calculated by the MRIA and the IEES - Flex models are higher. This may imply that allowing for more flexibility in the model results in higher losses in the affected region. In the MRIA model, this may be explained by the maximum regional capacity. In contrast to the ARIO and IEES models, the MRIA model sets a maximum capacity on the regional production (see Sect. 3.3). This regional maximum capacity prevents products which are normally considered as a byproduct from becoming the main product to its full extent. When a byproduct will be produced as a main product due to an increase in regional demand, taking into account the Leontief structure of an IO model, the production of the main product will go up as well. This induces the inefficien- cies in regional production that are limited by the regional production limit. As such, the model will turn more quickly to alternative suppliers from different regions, which do produce the demanded product as a main product, reducing the inefficient production overall. For the whole of Italy this results in lower losses compared to the ARIO model. In the IEES - Flex model, a similar substitution process occurs with the movement of production factors to other non-affected regions (not possible in the IEES - Rigid).

When comparing the spatial distribution of the losses across the three models for the concave recovery curve of the Emilia-Romagna flood (Fig. 4), we find some interesting results. First, the two "IO-based" models (i.e. the ARIO and MRIA models) show large differences in the spatial distribution of losses. Whereas the ARIO model shows negative results in all regions, the MRIA model only shows negative results in the affected region. What is notable is that the losses in the affected region are higher in the MRIA model (as also shown in Table 5). As such, by allowing for substitution between producers in the model, the affected region is affected more heavily, while the non-affected regions benefit. This can be explained by the inefficiency losses, which are modelled in the MRIA model, but not in the ARIO model. Second, we find some interesting similarities between the IEES Rigid and IEES - Flexible with, respectively, the ARIO and MRIA models. The rigid version of the IEES model, with immobile production factors, shows relative little substitution effects, resulting in negative (albeit small) effects in almost all non-affected regions. The flexible version, however, shows, similar to the MRIA model, benefits in all other regions due to large substitution effects. For the IEES models, it is important to note that the productivity shocks decrease the demand for labour and capital because of lower productive capacity and income. This means that remunerations of capital and labour go down and in the IEES - Flexible model capital, and labour can move towards non-affected regions. This determines the exacerbation of the profit and losses dynamics and is the main cause for the difference in regional economic losses between the IEES - Flexible and - Rigid model.

Figure 5 shows a comparison of the results presented in Table 4 (the left box plots for Veneto and Emilia-Romagna in Fig 5) with the same modelling set-up but without additional 


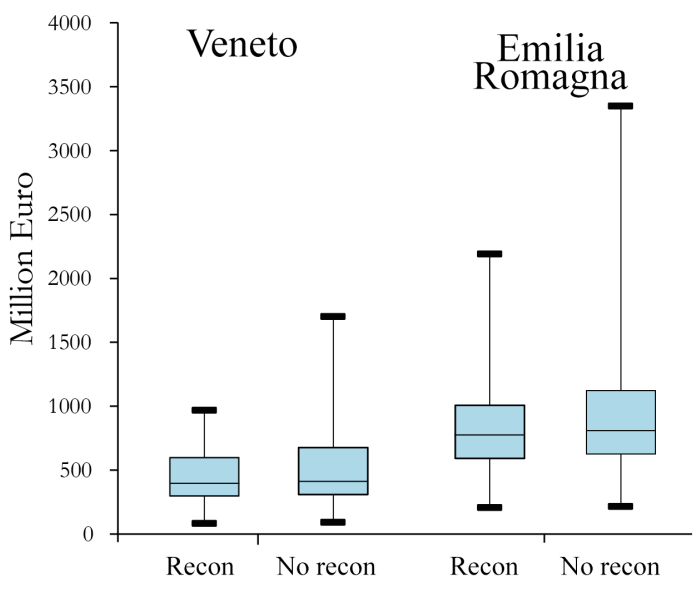

Figure 5. Comparison of losses with and without reconstruction demand for the two flood scenarios.

reconstruction demand due to the disaster (the right box plots for the two scenarios). The figure shows that not considering reconstruction demand in the model results not only in higher losses but also in a larger difference in losses between the several recovery curves within one flood scenario. The difference can be addressed in the increase in production (and thus increase in value added) due to the increased reconstruction demand from the affected sectors towards the construction sector. Important to note is that mainly the outliers change; for both the Veneto and Emilia-Romagna scenario, the median losses remain almost the same between the reconstruction and no reconstruction methods. From Fig. 5 we can interpret that especially with higher losses and slower recovery (the highest losses occur, as can be seen in Table 4, in the convex and linear recovery curves), including reconstruction demand will substantially reduce the total output losses.

\section{Discussion}

In our comparison exercise the ARIO model, but also traditional multiregional IO models in general, is lacking the capacity to estimate the potential substitution effects in other regions. This can be seized in CGE or (non-)linear programming methods, as shown by the MRIA and IEES models. Both the MRIA and IEES model can show how substitution effects can dampen the negative effects of a disaster in a larger economic entity. Due to the linearity of IO models, other regions always yield losses, which is consistent with results in MacKenzie et al. (2012) and in den Bäumen et al. (2015). However, this is contrary to the expected gains in non-affected regions around the affected area (see e.g. Albala-Bertrand 2013). Hence it is highly unlikely that all regions will suffer losses. In contrast, it is in a real situation also unlikely that substitution in production between regions is possible without any barriers to trade and movements of production factors.
Although the empirical literature finds that the sign and size of population responses vary substantially between different flood events, there is some evidence of post-disaster labour mobility. Husby et al. (2014) find that the largescale flood in the Netherlands as well as the reconstruction activities following the 1953 flood had a positive longterm effect on population growth in affected municipalities. This study thus finds some evidence that the reconstruction of affected areas was not restricted by fixed labour force. Nonetheless, since much is still unknown on the potential post-disaster movement on capital and labour, more empirical studies should analyse the post-recovery process in highincome countries.

Besides the differences in multiregional spill-over effects, two additional results within this paper contribute to the current literature. First, the losses in the affected region (Table 5) itself are relatively similar throughout all model set-ups compared to the losses for the whole of Italy (Table 4). This indicates that the different multiregional models considered in this study all capture the economic effects for the region directly affected by the flood in a similar order of magnitude. In West (1995) and Hu et al. (2014), the differences in outcomes between the IO and CGE models are much larger (in relative terms) in a single-economy framework. This implies that the difference in use between the multiregional models is less of an issue when one wants to know what the impacts are for the flood-affected region(s). Second, the mobility of capital and labour across sectors and regions in the IEES model and the inefficiency costs of the MRIA model can indicate how resilient an economy is, both on a regional and national level. Large interregional mobility effects (IEES) or high inefficiency costs (MRIA) within the affected region may indicate that the region struggles with the impact of a disruption. However, as also shown by the positive results in the other (non-affected) regions, the national economy may be rather resilient, with low inefficiency and high factors mobility. The ARIO model, using a more traditional IO framework, may be less straightforward in interpreting the economic resilience, lacking the characteristics of either inefficiency costs or mobility effects.

A better understanding of production losses is important for public budgeting, as well as for private resilience choices. On the public income side, a drop in production implies lower tax proceeds and other revenues in the current, and possibly in future, accounting periods. Even if the production is restored quickly, the losses of affected firms can influence state revenues through tax deductions conceded in the subsequent periods. On the spending side, post-disaster recovery programs and restoration of public infrastructure inure financial obligations which may increase government debt. Unfolded through cumulative or cascading paths, a series of medium-sized disasters or single large disasters may produce or aggravate existing economic imbalances and expand disparities across states or regions. It would be wise to consider economic risk embodied in natural hazards as 
a liability. The European Cohesion Policy measures states' economic performance using gross domestic product (GDP), GRP, and gross national income (GNI). Both are susceptible to disaster risk in a way that is not fully understood. Considering disaster risk as liability would help to prevent countries and regions from satisfying economic performance thresholds in one period but not in the next one. The GNI and GRP are also referred to in the thresholds that trigger solidary financial assistance through the European Solidarity Fund (EUSF). In this context the threshold is specified as a ratio of structural damage to GNI or GRP. In principle, the solidarity payments would be better targeted if triggered by the post-disaster drops in GNI/GRP or public revenues collected. The recent advancements in economic risk assessment, as presented in this paper, make it possible to base similar decisions on sound and robust knowledge.

\section{Concluding remarks}

In this study we have analysed several risk scenarios in a pilot study area using three regional economic models: two hybrid multiregional IO models (ARIO and MRIA) and a regionally disaggregated instance of a global CGE model (IEES). The pilot study area is located in the downstream part of the Po River. The two flood scenarios comprise levee breaks on a Po River levee at the same place where it occurred in 1951. The economic losses for the flood scenarios have been calculated for all three models, using three different recovery paths (concave, convex, and linear).

Relatively large differences in model outcomes have been found on the national scale for all flood scenarios and considered recover paths. The most substantial differences were found between the ARIO model on the one hand and the MRIA and the IEES models on the other hand (results vary by up to a factor of 7). Differences between the MRIA and the IEES models were relatively minor, whereas the results of the ARIO model were approximately 3 to 6 times higher compared to the results of the IEES model for Italy as a whole. The main reason for this difference is the linear structure assumed in the ARIO model and its lack of substitution in production, trade, or products. Due to the linear characteristics of the model, all other (non-affected) regions will be negatively affected due to the disaster. We argue that this negative effect for all other regions may not be realistic and, therefore, we suggest that multiregional disaster impact studies should apply more flexible economic models such as the MRIA or IEES models.
The different recovery paths showed that the speed of recovery is crucial for the total losses. A quick recovery (a concave recovery path) results in substantial lower losses compared to a slow recovery (convex recovery path). This outcome is observed in all three models. The empirical research on this, however, is rather limited. As such, future research is required to explore which recovery paths are empirically observed and what resilience measures are required to make sure an affected area will be recovered quickly to reduce losses. We argue that solutions could be explored in the field of public-private partnerships.

This study showed that some model outcomes are susceptible to underlying assumptions, while others are not. Therefore, for a detailed assessment of disaster impacts on economy, including the price effects and effects on employment, the CGE models are better suited. For assessing cost-benefit ratio of specific resilience measures, both the MRIA and the IEES model seem to be equally useful and produce similar outcomes in terms of output losses. The conventional multiregional IO models may largely overestimate the losses. For future research, more empirical data are needed to better explore the trade-off between the analysed models.

\section{Data availability}

The PBL data on multiregional supply and use tables as used in this paper are available on request from the corresponding author. The original source data are available for the purpose of transparency and checking the outcomes obtained with this paper on request from the PBL Netherlands Environmental Assessment Agency. The interregional trade data that are part of this dataset are largely made publicly available on the European Regional Competitiveness Scoreboard (http://themasites.pbl.nl/eu-trade/). GTAP 8 data are covered by a license. Documentation on the dataset can be found at https://www.gtap.agecon.purdue.edu/databases/v8/ v8_doco.asp. Italian data which have been used to split the GTAP 8 data for Italy can be found at http://www.istat.it/it/ archivio/12718. GIS-based local data are not publicly accessible due to its protection level (owned by local authorities). 


\section{Appendix A}

Table A1. List of sectors considered in the MRIA, ARIO, and IEES models.

Agriculture

Mining, quarrying, and energy supply

Processed foods

Light manufacturing

Heavy manufacturing

Construction

Transport, storage, and communications

Services 
Acknowledgements. The research underlying this paper has received funding from the EU Seventh Framework Programme (FP7/2007-2013) under grant agreement no. 308438 (ENHANCE - Enhancing risk management partnerships for catastrophic natural hazards in Europe), grant agreement no. 282834 (TURAS Transitioning towards urban resilience and sustainability), grant agreement no. 603396 (RISES-AM - Responses to coastal climate change: Innovative Strategies for high End Scenarios - Adaptation and Mitigation), and grant agreement no. 609642 (ECOCEP - Economic modelling for ClimateEnergy Policy), the Italian Ministry of Education, University, and Research and the Ministry for Environment, Land, and Sea (the 25 GEMINA project), and NWO VICI grant agreement no. 45314006. The paper is supported by "The Hazard and Risk Science Base at Beijing Normal 25 University" (no. B08008).

Edited by: M.-C. Llasat

Reviewed by: R. Pant and one anonymous referee

\section{References}

Albala-Bertrand, J. M.: Disasters and the Networked Economy, Routledge, Oxon, UK, 2013.

Baghersad, M. and Zobel, C. W.: Economic Impact of Production Bottlenecks Caused by Disasters Impacting Interdependent Industry Sectors, Int. J. Prod. Econ., 168, 71-80, 2015.

Bockarjova, M.: Major disasters in modern economies: An inputoutput based approach at modelling imbalances and disproportions, University of Twente, Twente, 2007.

Carrera, L., Standardi, G., Bosello, F., and Mysiak, J.: Assessing direct and indirect economic impacts of a flood event through the integration of spatial and computable general equilibrium modelling, Environ. Modell. Softw., 63, 109-122, 2015.

Cavallo, E. and Noy, I.: The Economics of Natural Disasters: A Survey, IDB Working Paper, No. 124, Washington DC, InterAmerican Development Bank, 2009.

Cho, S., Gordon, P., Moore, I. I., James, E., Richardson, H. W., Shinozuka, M., and Chang, S.: Integrating transportation network and regional economic models to estimate the costs of a large urban earthquake, J. Regional Sci., 41, 39-65, 2001.

Ciscar, J. C., Feyen, L., Soria, A., Lavalle, C., Raes, F., Perry, M., Nemry, F., Demirel, H., Rozsai, M., Dosio, A., Donatelli, M., Srivastava, A., Fumagalli, D., Niemeyer, S., Shrestha, S., Ciaian, P., Himics, M., Van Doorslaer, B., Barrios, S., Ibáñez, N., Forzieri, G., Rojas, R., Bianchi, A., Dowling, P., Camia, A., Libertà, G., San Miguel, J., de Rigo, D., Caudullo, G., Barredo, J.-I., Paci, D., Pycroft, J., Saveyn, B., Van Regemorter, D., Revesz, T., Vandyck, T., Vrontisi, Z., Baranzelli, C., Vandecasteele, I., e Silva, F., and Ibarreta, D.: Climate Impacts in Europe, Results from the JRC PESETA II Project, European Commission (EC), Joint Research Centre (JRC), Ispra, Italy, 2014.

Cobb, C. W. and Douglas, P. H.: A theory of production, Am. Econ. Rev., 18, 139-165, 1928.

Crowther, K. G. and Haimes, Y. Y.: Application of the inoperability input-output model (IIM) for systemic risk assessment and management of interdependent infrastructures, Syst. Eng., 8, 323$341,2005$.
Hallegatte, S.: An adaptive regional input-output model and its application to the assessment of the economic cost of Katrina, Risk Anal., 28, 779-799, doi:10.1111/j.1539-6924.2008.01046.x, 2008.

Hallegatte, S.: Modelling the role of inventories and heterogeneity in the assessment of the economic costs of natural disasters, Risk Anal., 34, 152-167, 2014.

Hertel, T. W.: Global trade analysis: modelling and applications, Cambridge University Press, 1997.

Hu, A., Xie, W., Li, N., Xu, X., Ji, Z., and Wu, J.: Analyzing regional economic impact and resilience: a case study on electricity outages caused by the 2008 snowstorms in southern China, Nat. Hazards, 70, 1019-1030, 2014.

Husby, T. G.: Economic impacts of behavioural responses to flood risk, doctoral dissertation, Vrije Universteit Amsterdam, Amsterdam, 2016.

Husby, T. G., Groot, H. L. F., Hofkes, M. W., and Dröes, M. I.: Do floods have permanent effects? Evidence from the Netherlands, J. Regional Sci., 54, 355-377, 2014.

in den Bäumen, H. S., Többen, J., and Lenzen, M.: Labour forced impacts and production losses due to the 2013 flood in Germany, J. Hydrol., 527, 142-150, doi:10.1016/j.jhydrol.2015.04.030, 2015.

IPCC: Managing the Risks of Extreme Events and Disasters to Advance Climate Change Adaptation, A Special Report of Working Groups I and II of the Intergovernmental Panel on Climate Change, edited by: Field, C. B., Barros, V., Stocker, T. F., Qin, D., Dokken, D. J., Ebi, K. L., Mastrandrea, M. D., Mach, K. J., Plattner, G.-K., Allen, S. K., Tignor, M., and Midgley, P. M., Cambridge University Press, Cambridge, UK, and New York, NY, USA, 582 pp., 2012.

Jongman, B., Kreibich, H., Apel, H., Barredo, J. I., Bates, P. D., Feyen, L., Gericke, A., Neal, J., Aerts, J. C. J. H., and Ward, P. J.: Comparative flood damage model assessment: towards a European approach, Nat. Hazards Earth Syst. Sci., 12, 3733-3752, doi:10.5194/nhess-12-3733-2012, 2012.

Kim, T. J., Ham, H., and Boyce, D. E.: Economic impacts of transportation network changes: Implementation of a combined transportation network and input-output model, Pap. Reg. Sci., 81, 223-246, 2002.

Koks, E. E. and Thissen, M.: The economic-wide consequences of natural hazards: an application of a European interregional inputoutput model, Conf. Pap. 22nd Input Output Conf., Lisboa, Port., 2014.

Koks, E. E., Bočkarjova, M., De Moel, H., and Aerts, J. C. J. H.: Integrated Direct and Indirect Flood Risk Modelling: Development and Sensitivity Analysis, Risk Anal., 35, 882-900, doi:10.1111/risa.12300, 2015.

MacKenzie, C. A., Santos, J. R., and Barker, K.: Measuring changes in international production from a disruption: Case study of the Japanese earthquake and tsunami, Int. J. Prod. Econ., 138, 293 302, doi:10.1016/j.ijpe.2012.03.032, 2012.

Merz, B., Kreibich, H., Schwarze, R., and Thieken, A.: Review article "Assessment of economic flood damage", Nat. Hazards Earth Syst. Sci., 10, 1697-1724, doi:10.5194/nhess-10-16972010, 2010.

Narayanan, B. G. and Walmsley, T. L.: Global trade, assistance, and production: the GTAP 7 data base, Cent. Glob. trade Anal. Purdue Univ., 134, 2008. 
Narayanan, B., Aguiar, A., and McDougall, R.: Global Trade, Assistance, and Production: The GTAP 8 Data Base, Center for Global Trade Analysis, Purdue University, West Lafayette. 2012.

Okuyama, Y.: Economics of natural disasters: A critical review, Res. Pap., 12, 20-22, 2003.

Okuyama, Y.: Globalization and Localization of Disaster Impacts: An Empirical Examination, in: CEFifo Forum, vol. 11, 56-66, 2010.

Okuyama, Y.: Disaster and economic structural change: case study on the 1995 kobe earthquake, Econ. Syst. Res., 26, 98-117, doi:10.1080/09535314.2013.871506, 2014.

Okuyama, Y. and Chang, S. E.: Modelling spatial and economic impacts of disasters, Springer, 2004.

Okuyama, Y. and Sahin, S.: Impact Estimation of Disasters: A Global Aggregate for 1960 to 2007, World Bank ${ }^{\circledR}$ World Bank, https://openknowledge.worldbank.org/handle/10986/4157 Licens. Creat. Commons Attrib. CC BY 3.0., 2009.

Okuyama, Y. and Santos, J. R.: Disaster impact and input-output analysis, Econ. Syst. Res., 26, 1-12, 2014.

Okuyama, Y., Hewings, G. J. D., and Sonis, M.: Measuring economic impacts of disasters: interregional input-output analysis using sequential interindustry model, edited by: Okuyama, Y. and Chang, S., Model. Spat. Econ. Impacts Disasters, Springer, Heidelberg, 77-101, 2004.

Park, J., Cho, J., Gordon, P., Moore II, J. E., Richardson, H. W., and Yoon, S. : Adding a freight network to a national interstate input-output model: a TransNIEMO application for California, J. Transp. Geogr., 19, 1410-1422, doi:10.1016/j.jtrangeo.2011.07.019, 2011.

Rose, A.: Input-output economics and computable general equilibrium models, Struct. Chang. Econ. Dyn., 6, 295-304, 1995.

Rose, A.: Economic principles, issues, and research priorities in hazard loss estimation, in Modelling spatial and economic impacts of disasters, doi:10.1007/978-3-540-24787-6_2, 2004.

Rose, A. and Liao, S.-Y.: Modelling regional economic resilience to disasters: A computable general equilibrium analysis of water service disruptions*, J. Regional Sci., 45, 75-112, 2005.

Rose, A. and Wei, D.: Estimating the economic consequences of a port shutdown: the special role of resilience, Econ. Syst. Res., 25, 212-232, 2013.
Rose, A., Benavides, J., Chang, S. E., Szczesniak, P., and Lim, D.: The regional economic impact of an earthquake: Direct and indirect effects of electricity lifeline disruptions, J. Regional Sci., 37, 437-458, 1997.

Santos, J. R. and Haimes, Y. Y.: Modelling the Demand Reduction Input-Output (I-O) Inoperability Due to Terrorism of Interconnected Infrastructures*, Risk Anal., 24, 1437-1451, 2004.

Seung, C. K.: Measuring spillover effects of shocks to the Alaska economy: an inter-regional social accounting matrix (IRSAM) model approach, Econ. Syst. Res., 26, 224-238, doi:10.1080/09535314.2013.803039, 2014.

Shibusawa, H., Yamaguchi, M., and Miyata, Y.: Evaluating the Impacts of a Disaster in the Tokai Region of Japan: A Dynamic Spatial CGE Model Approach, Stud. Reg. Sc., 39, 539-551, 2009.

Standardi, G., Bosello, F., and Eboli, F.: A sub-national version of the GTAP model for Italy, Work. Pap Fond. Eni Enrico Mattei, 1-20, 2014.

Taylor, L. and Lysy, F. J.: Vanishing income redistributions: Keynesian clues about model surprises in the short run, J. Dev. Econ., 6, 11-29, 1979.

Thissen, M.: The indirect economic effects of a terrorist attack on transport infrastructure: A proposal for a SAGE, Disaster Prev. Manag., 13, 315-322, 2004.

Thissen, M. and Lensink, R.: Macroeconomic effects of a currency devaluation in Egypt: An analysis with a computable general equilibrium model with financial markets and forward-looking expectations, J. Policy Model., 23, 411-419, 2001.

Thissen, M., van Oort, F., Diodato, D., and Ruijs, A.: Regional Competitiveness and Smart Specialization in Europe: Placebased Development in International Economic Networks, Edward Elgar Publishing, 2013.

Tsuchiya, S., Tatano, H., and Okada, N.: Economic Loss Assessment due to Railroad and Highway Disruptions, Econ. Syst. Res., 19, 147-162, doi:10.1080/09535310701328567, 2007.

UNISDR: Sendai Framework for Disaster Risk Reduction 20152030, 2015.

West, G. R.: Comparison of input-output, input-output+ econometric and computable general equilibrium impact models at the regional level, Econ. Syst. Res., 7, 209-227, 1995. 